\title{
The Justification of Authority and the Insulation of Formal Reasons
}

\author{
Cláudio Michelon*
}

The practical agent, faced with a choice between performing and refraining from petforming an action, has to decide not only what to do, but also how to fight her way through the pluralism she carries within. Elsewhere I claimed that there are moral reasons that apply to an agent's process of decision-making. Those reasons aim at solving the problems with which the agent is faced in trying to lead her life consistently. An agent trying to do the right thing would ask whether or not there is an obligation to always decide on reasons or whether or not public and private agents are morally required to use different strategies of decision-making. One of the most important questions one might ask about the morality of decision-making is how should reasons interact within a particular process of reasoning. Broadly speaking there seem to be at least two ways in which we can conceive that interaction: a) reasons might be weighed against one another and b) reasons might exclude other sorts of reasons from the very process of deliberation.

In the first situation (that is, the weighing of reasons against one another), we might say, to use J. Raz's terminology, that the defeated reason is excluded by weight, while in the second we might say, again following $\mathrm{R}_{a z}$, that the defeated reason was excluded by kind.

\footnotetext{
* Bacharel em Direito and M.Phil (Universidade Federal do Rio Grande do Sul, 1992, 1996); Ph.D. (University of Edinburgh, 2001); Lecturer in Law, Pontificia Universidade Católica do Rio Grande do Sul and Centro Universitário Ritter dos Reis; Invited Lecturer, Universidade Federal do Rio Grande do Sul. I am indebted to many friends for their criticism and the suggestions they made about the arguments I present here. Among them I speccially I wish to thank Zenon Bankowki, Emilios Christodoulidis, Fernando Atria and Kevin Walton.
} 
The problem I am directly concerned with in this article is whether or not legitimate authoritative rules can exclude moral reasons from the public agent's decision-making process. In other words, I shail be discussing the thesis that rules emanating from legitimate authorities are formal reasons. It has been said that one is not treating rules (or any other sort of authoritative decision, such as direct orders) as formal (authoritative) if one weighs the value of obeying the rule against the value of disobeying it. If an agent's practical decisionmaking process involves considerations which could lead to disoheying a rule, this agent would not by definition be treating this rule as authoritative. That implies that authoritative rules, if their authority is justified (legitimate), would have priority over other considerations in processes of practical decision-making. In this article I am specifically interested in one particular justification for that thesis, namely, the justification originally sketched by Joseph Raz in Practical Reasons and Norms, and later fully developed in The Morality of Freedom ${ }^{2}$. This papers is part of a project of tethinking formal reasons which is, in turn, part of a larger project of proposing an ethical theory that is applicable to decision-making processes and which is not fully dependent on the ethical theory that is applicahle to actions.

My argument aims at making the point that arguments such as the one put forward hy Raz by means of his 'normal justification' and 'pre-emption' theses cannot prove that reasons emanating from legitimate authoritative sources are able to exclude other reasons by kind from practical decision-making ${ }^{3}$. But before dealing directly with Raz's argument, I will say something about the sort of reasons politically created reasons can be. I shall identify then precisely which sort of politically created Raz's argument supposes authoritative reasons are. That approach will help to establish the different. senses in which authoritative orders might he said to interfere in a subject's autonomy and, in particulat, the different ways in which they can intervene in the subject's decision-making. I shall use this examination of the ways in which authority might inrervene in the subject's decision-making to inrroduce a distinction between reasons that make an action right and wrong (which I shall simply call 'reasons for

\footnotetext{
${ }^{1}$ As Atiyah has pointed out, Raz's conception of rules as exclusionary reasons hints precisely at that idea of formality. Rules properly understood are not rules of thumb to be checked against the actual substantive reasons; they exclude those reasons attogether from consideration. See P. S.

Atiyah, Form and substance in contract law, in The Legal Mind, ed. N. MacCormick and P. Birks, Oxford: Clarendon Press, 1986, 20-1; see also J. Raz, Practical Reasons and Norms (Princeton, Nj: Princeton University Press, 2nd edition, 1990), passim.

2 J. Raz. The Morality of Freedom (Oxford: Clarendon Press, 1986).

${ }^{3}$ Because legal rules are the patadigmatic instance of authoritative tules, I shall often be referring to them in what follows, but that does not mean that my arguments do not apply to other sorts of authoritative directives.
} 
action') and reasons one should use in order to decide particular cases (which I shall call 'reasons to decide'). I believe that Raz's normal justification thesis applies not to the former, but to the latter sort of reason and the second section of this article is an attempt to establish whether or not Raz's atgument is sufficient to justify an instuation between legal and moral teasons for deciding. The third sections will be an attempt to outline an altemative account of formal reasons in which they are not insulated from substantive consideration but, rather, interact with those sorts of considerations in a particular way.

\section{Authority and Autonomous Decision-Making}

Let me start by mapping up the field of authoritative intervention on decisionmaking processes in order to clarify what sorts of intervention I am claiming cannot be justified. First, political authority might intervene on its subjects decision-making process simply by preventing their decision-making altogether. If political authority does have enough raw power to prevent me from having a choice on a particular matter, it takes from me the very possibility of deciding to do certain things. The agent's practical reasoning is eliminated and substituted by the authority's reasoning. A policeman who locks someone up is not creating a reason for the person not to go to a dinner party in, it is making the decision of whether or not to go to the dinner pointless. I have no doubt that it is possihle to find a justification for this sort of intervention in certain very qualified contexts, but that is not the sort of intervention I am dealing with in this paper.

Secondly, and quite apart from directly exerting force against its members, the community might intervene in the very process of deliberation through which the person decides what is the best course of action. One way in which this intervention might come about is simply by means of threats of using force. When the authority issues a statement in which it declares that all those who perform a certain action (say, assault) will be imprisoned for a certain time, it is not exerting force directly, but simply attempting to intervene in the decision-making process of the subject by means of creating a reason to perform an action. That is not what Raz means by authoritative intervention, since anyone who is in a position of threatening someone else would have that sort of 'authority'.

Indeed, the authoritative intervention in an agent's process of decision-making takes more subtle forms. An example might help to explain those more subtle forms of authoritative intervention. Suppose that, after some thinking, I arrive at the conclusion that you should do something, for instance, that you should read my last book, and then I tell you of my conclusion. How can my saying that you should read my book change your previous situation regarding the range of options open to you as to whether or not to read my book? It could be that you take my decision to express a fact that you believe to be relevant for the decision you ate about to make. In this situation, the communication of my conclusion about how you should behave would only have a bearing on your possihilities of decision if it gives some information about the world that is in itself a relevant piece of information. If we assume that you care about my well-being, informing you that I would be sad were you not to read my book would give you a good reason to read it. The decision 
could then be interpreted not as a command, but as a desctiption of a given state of affairs ${ }^{4}$. It gives you a reason to believe that a given fact is the case, but not necessarily a teason to believe that the fact is a reason for action. The best way to show that that intervention should not be conceived as 'authoritative' is to ask whether or not this sort of intervention in a decision-making process is detrimental to the decision maker's autonomy?

It would seem that it isn't, for after my intervention (stating that you should tead my book) you are still a fully autonomous decision-maker if only a bit better informed about the facts and possible factual consequences of your decision. I can still manipulate you by providing selective information ot by telling lies that $I$ think will bring you to decide in one way rather than another. Nevertheless tbere is no reason why my opinion should be taken into consideration in its own right. This is cleat in two different situations: first, had you learned abour the facts that you infer from my telling you that you should read my book before I told you to do so, your possibilities of decision wouldn't be changed by my supervening intervention; secondly, had you learned about those facts through completely different means (someone told you that I would be upset if you decided not to read my book), the outcome would be the same. Of course, there is a sense in which providing information changes the motal landscape of an individual. If, for instance, I know that my performing action $\mathrm{x}$ (buying a car) will have consequence $\mathrm{y}$ (someone will die), I cannot use my lack of knowledge as a moral excuse for my having performed $\mathrm{x}$. Information might exclude one possible excuse from my moral estate.

However, there is a different way of interfering in someone's affairs which has a different sort of bearing on his practical reasoning and which is of particular interest for the understanding of political and specifically legal authority. Under some conditions, my statement that you should read my book may be relevant in itself, which means that the fact that $I$ reached a given conclusion and that $I$ told you about it may itself be a reason for you to decide to act according to my conclusion. That means that nothing changes in the world as a result of my statement, nothing about pre-existing facts is learned from my statement, the only difference between your situation before my statement and after my statement is the fact that I said tbat you should do something. I believe that to be perfectly conceivable, given certain circumstances, but I shall return to that latter.

Because that is a change in the criteria for the correctness of decision-making, nothing in principle guarantees that the reason created will or should prevail against all other reasons available to the subject in her actual decision-making process. Whether or not my conclusion

\footnotetext{
"In spite of the apparent similarity, this sort of intervention in the deliberative process is not the same sort of intervention that might be produced by the authority Raz called

'recognitional'. In Raz's depiction of the recognitional conception of authority "[t]he authoritative utterances of practical authority are reasons to believe that one ought to do that which the utterance says one is to do". (J. Raz, The Morality of Freedom, cit., 30). The interference in practical reasoning sketched above doesn't provide you with any reason to believe that a given course of action is the correct one, but only with a reason to believe that a given situation obtains (a situation that you happen to find relevant to your decision).
} 
that you should read this book is a relevant factor in your actual process of deliberation depends on you attributing some value to it (say, the value of pleasing a friend). The decision itself is not self-enforcing in this sense and you are still autonomous in the important sense that you are not obliged to take my conclusion into consideration. That sort of interfetence (obliging someone to give weight to one's statement about what should be done in her process of deliberation) could be achieved through many different methods of conditioning deliberative behaviot by force or by argument, hut, as Hart once pointed out 'heing obliged' is different from 'having an obligation'.

In order to understand the sort of interference in decision-making processes I will be referring to as 'authoritative', it is important to bear in mind that rational decision-making processes always aim at correctly weighing up the reasons. If this is so, there is a sense in which your selection of reasons is not arbitrary. In the Clouds, Aristophanes mocks Socrates (and through Socrates the whole of practical philosophy) for he leaves the stage when the exchanges between Justice and Injustice are about to start ${ }^{5}$. According to Leo Strauss, this makes it appear as if Socrates wanted to have no influence on the exchanges so that he would not he responsible for the ourcomes. If one wanted to he fair to Socrates (which is probably not Aristophanes' wish), one could take his acr of leaving the stage as meaning simply that what makes an action just or unjust or a process of deliberation correct or incortect is not dependent on the opinion held by the decision-maker about what should count as a just action or a correct deliheration. The meaning of Socrates' lack of interest in the exchange hetween justice and injustice might be seen as an allegory of the fact that, whatever the correct balance of reasons is, it is not dependent on the subject's opinion on what the right halance of reasons should be. Moreover, the reasons that come into play when a motal agent is weighing reasons against one another in order to decide what to do are not freely chosen by the agent. Soctates' presence is, then, of no consequence. In short: one might have some control over the reasons one actually take into account in deciding what to do, but one has little or, sometimes, no control whatsoever, over the reasons that must be taken into account in order to decide wbat to do.

Now suppose that, under some citcumstances, someone's actions have the power to alter someone else's moral situation by including further reasons among the reasons which morally should be taken into consideration and weighed by the decision-maker. If those circumstances ohtain, someone's action will cause the inclusion of one reason in the list of relevant reasons that should be taken into account by someone else. What was changed as a

\footnotetext{
5 The Clouds, 886-7

${ }^{6}$ This is Strauss's interpretation of Socrates's exiting from the stage at precisely that moment. Leo Strauss Socrates and Aristophanes (Chicago: The University of Chicago Press, 1966), 28-9.
} 
result of the first agent's action was the criterion for correctness of the second agent's decision-making process and this has a particular sott of impact on the lattet's autonomy. Through this sort of intetvention, one is not only modifying actual decision-making processes by including or excluding reasons, but modifying the standard for what would be the right decision-making process in the particular circumstances. An authoritative intervention in someone's autonomy is an intervention of ptecisely that kind.

Reasons for decision and Reasons for Action

Before I move on to deal directly with Raz's argumenr for the justification of that sott of intervention on an agent's decision-making, I would like to deal with an ambiguity in the phrase 'reasons for action'. If that ambiguity is not fully spelled out, I believe the conception of authority I just put forward in the last section might be misundetstood. On the one hand, 'reason for action' can be understood as a fact ot set of facts whose occurrence in the world makes it correct to perform a given action?. An example might help me to conduct the discussion here. In the limited context of deciding how to invest your money and, given that the only relevant considerations are those related to the inctease of capital over time, the fact that the government is soon to intervene in the market so as to devalue the national currency is a good teason for deciding to invest in foreign curtency. If this is what is meant by saying that there is a 'reason for action', the only way I can intervene in the criteria according to which your decision-making is judged is by changing something in the world. In out example, if the government changes its mind and decides not to devalue the currency the reason for investing in foreign currency that you had hefore disappears and such investment, otber things being equal, would be not as good an investment.

On the other hand, 'reason for action' might tefer to a reason one takes, or should take, into account in a deliberative process. Let me call those reasons 'reasons for deciding to perform a given action' (ot more briefly 'reasons for deciding') so as to reserve 'reasons for action' to the changes in the world mentioned in the last paragraph. The difference I am trying to draw attention to is often misunderstood as a tesult of taking it as a difference between reasons which exist objectively speaking and the possession of those reasons by the subject. If this were correct, it would seem to follow that all the reasons one should take into account in decision-making processes would be the objective reasons for actions that exist in the world. The difference between reasons for action and reasons for deciding would simply be tbat the latter, but not the former, are used by a particular subject. That means that if the decision-making process is to be considered correct, all reasons for deciding would be objective reasons for action which already existed in the world before being 'enbodied' into the particular decision-making

\footnotetext{
' See J. Raz, Practical Reasons and Norms, cit., $16 \mathrm{ff}$; see also M. J. Detmold The Unity of Law and Morality (London: Routledge \& Kegan Paul, 1984), pP 8 ff.
} 
process. I believe this conception of reasons for deciding to be insufficient. In decisionmaking processes carried out under imperfect conditions, notably conditions of limited knowledge or limited time to decide, there are often reasons for deciding in a particular way rather than another which are not objective reasons for the action in the sense referred to above. In order to show this, let us go back to a variation of the example introduced above.

Suppose I have to decide how to invest my money but I haven't the faintest idea of what would be the best way to get a good profit/time ratio for my money. I then take the wise step of consulting an expert who is, I have reasons to believe, the best advisor I could get, and he tells me to invest all my money in foreign currency. I now have reasons to invest in foreign currency and, other things remaining the same, deciding to invest in something else would be a mistake. One might say that I don't have a reason to decide to do something, but only a reason to believe that some facts ate the case, and that those facrs are actually the case is a reason for me to decide to invest in foreign currency. That is true, but it is hardly an objection to the point I am trying to make. In order to make it clear why, let us suppose now that the expert is wrong because the government never thought of devaluing the national currency or because orher factors the expert never considered relevant come into play so that the price of foreign currency doesn't actually rise much even after the government's intervention. As an investment, my buying foreign currency was disastrous, bur there is a sense in which my decision was not a mistake. Otherwise, one would bave to admit that the right decision in the case would have been to trust someone who knows nothing about investment (me) instead of the person I recognise as someone who knows a lot about it. If I am right, a rationally correct decision (which takes into account the correct reasons for deciding) does nor necessarily lead to a correct action. Consequently, reasons to decide in a correct decision-making process are not necessarily the reasons for action which are in the world. To sum up: it is possible that I make the right decision to do the wrong thing.

Let us now leave financing aside and move hack into the ethics of public decisionmaking which is, after all, the main concern of this paper. The first thing that has to be settled is the relevance of all that to ethics. The relevance is simply that having taken the right decision often works as a moral excuse for those who perform wrong actions. If I did everything I could do, given nay limitations which I cannot eliminate before performing the action, and if I correctly balanced my reasons to decide under those conditions of limitation, I have a claim to be excused, although it may sometimes not be enough ${ }^{8}$.

Reasons for action and reasons for deciding ate both practical in the sense that one can judge through those reasons either the correctness of the action or the correctness of the decision

\footnotetext{
${ }^{8}$ am grateful to Fernando Atria for this insight.
} 
to act. Although political power can create reasons for action, for instance, by deciding to impose sanctions on a given action, I believe that the kind of authoritative reasons Raz has in mind ate reasons for deciding rather than reasons for action. On this reading of Raz, the peculiarity of authoritative decisions seems to reside in the fact that the action which changes someone's motal landscape is just a statement by the public authority about how the agent should act. Raz's normal justification thesis could then be understood as an attempt to state the general conditions under which this sort of interference by the political authority in the subject's autonomy is justified. I shall analyse Raz's normal justification thesis in the next section, but let me just make clear that, beside Raz's, there are other possible justifications for someone to have the power to intervene in someone's autonomy. When, for instance, a conclusion about how you should behave comes from someone that you have reasons to believe to be much wiser than you are, it must be correct to trust his judgement. In this case, beside the reasons that I take into consideration, I put the opinion of the wise man and I am justified in doing so".

Those holding political power very often claim to have authority in this sense, that is to say they claim that all those towards whom they have authority have a moral ohligation to take their directives as reasons for deciding to act in the recommended way. Law is one sort of institution that claims authority if not always, as Raz, Soper, Green and others ${ }^{\text {to }}$ believe, at least often enough. One of the questions for practical philosophers to answer is under which conditions this claim is justified ${ }^{11}$. Not all theories of political obligation have a hearing on the problem I am more directly concerned with in this paper, namely, the insulation hetween legal and non-legal reasons ${ }^{12}$. Raz's theory of political obligation does. I shall devote the second section of the present paper to showing that Raz's theory of political authority fails to justify the exclusion non-authoritative reasons for deciding from those decision-making processes to which authoritative reasons for deciding apply.

Pre-emption in Legal Reasoning

The main concern in this paper is, as it was said before, to provide an account of the interplay between authoritative legal teasons and non-legal teasons for action in practical reasoning and, more specifically, of the sense in which authoritative legal reasons can be said rightly to exclude other sorts of substantive considerations from particular instances of

\footnotetext{
'This example is an instance of Raz's 'normal justification thesis', to be examined later in this paper.

10) See J. Raz, Morality of Freedom, cit, 76-77; a more recent restatement is to be found in Raz, Authority, law and morality in J. Raz, Ethics in the Public Domain: Essays in the morality of law and politics (Oxford: Clarendon Press, 1994), 215ff; Soper accepted that law makes authoritative ctaims in his Legal theory and the claim of authority, in Philosophy and Public Affairs 18, 216ff, but later rejected this thesis in Law's normative clains, in: The Autonomy of Law ed. R. P. George Oxford, Clarendon Press, 1996, 215-247; see also L. Green The Authority of the State (Oxford: Oxford University Press, 1988), esp. chapters 8 and 9.

"See R. Dworkin Law's Empire (London: Fontana Press, 1991; orig edn 1986), 191.

12 It is, for instance, irrelevant whether the obligation to obey the law is a natural duty or an acquired obligation.
} 
practical reasoning. One of the most important contemporary defenses of the exclusion of substantive considerations by legitimate legal reasons for action is to be found in Raz's work on legitimate authority and pre-emptive reasons for action.

Raz's pre-emptive reasons have been subject to intense scrutiny over the past two decades ${ }^{13}$. Instead of restating those objections to Raz's concept of pre-emptive teasons I shall be trying to explain in what follows why I believe tbat Raz's pre-emptive reasons fail to do the job he requires from them in terms of bis own theory. Let me first advance my thesis: in order to be able to exclude first-order moral reasons, second-order reasons (of which 'preemptive' reasons are an instance) first-order reasons must be completely insulated from preemptive reasons, that is to say: regardless of its weight, first order reasons must not be able to defeat second order reasons. I believe that the reason Raz offers for considering legal reasons as second-order reasons (fundamentally, the normal justification thesis) does not do the job and the argument in this section aims at proving that the normal justification thesis is nor able to ground the exclusion of exclusionary reasons from decision-making processes ${ }^{14}$. It would follow tbar, in the case of legal reasons at least, the weight of firstorder reasons might make a difference as to whether or not the second-order reason applies and, as a result, legal decision-making processes must include an appreciation of the weight of first-order reasons.

Let me start to expose my argument by analyzing Raz's normal justification thesis, which expresses the nomal condition to be fulfilled by legitimate authority:

The normal and primary way to establish that a person should be acknowledged to have aurhority over another person involves showing that the aileged subject is likely better to comply witb reasons that apply to him (other than the alleged authoritative directives) if

\footnotetext{
${ }^{13}$ Just to mention a few, M. J. Detmold, The Unity of Law and Morality, cit., 133ff; Soper, "Legal theory and the claim of authority", cit; F. Schauer: Playing by the Rules: A philosophical examination of rulebased decisionmaking in law and in life (Oxford: Clarendon Press, 1991), passim; A. Marmor Interpretation and Legal Theory (Oxford: Oxford University Press, 1984), 117ff; F. Atria: Legal reasoning and legal theory revisited, Law and Philosophy 18 (1999), 566 ff.

${ }^{14}$ That is the problem Detnold named the problem of the exclusion of exclusionary reasons ( The Unity of Law and Morality, cit, 134). Detmold himself believes that there are arguments that are indeed able to exclude exclusionary reasons (id, 133-36). I shall not dispute the matter here, for I believe that, regardless of whether or not there are arguments that are able to justify this double exclusion, the argument put forward by $\mathrm{Raz}$ to insulate legal reasons from first-order reasons is not one of them.
} 
he accepts the directives of the alleged authority as authoritatively binding, and tries to follow them, than if he tries to follow the reasons which apply to him directly. ${ }^{\text {is }}$

To sum it up; authority might create reasons for deciding from scratch whenever it is more likely to get it right than you are. This condition for the legitimacy of someone's authority, says Raz, at the same time reinforces and is reinforced ${ }^{16}$ by the imperative expressed in the dependence thesis, according to which

All authoritative directives should be hased, among other factors, on reasons which apply to the subjects of those directives and which hear on the circumstances covered by the directives. ${ }^{17}$

If the condition stated in the normal justification thesis is met, authority is legitimate and it is morally correct for the subject to perform the action required by the authority without taking into account the reasons that would apply to him if the authoritative directive had not been issued. This amounts to a very rough version of the pre-emption thesis, whose full statement is:

The fact that an authority requires performance of an action is a reason for its performance which is not to be added to all other relevant reasons when accessing what to do, but should replace some of them.

The pre-emptive thesis was formulated so that it conrradicts another account of how authoritative directives (including authoritative legal rules) relate to other reasons for action. According to this alternative account:

to accept the legitimacy of an authority is simply to accept that whatever other reasons there may be for a certain action, its being required by the authority is an additional reason for its performance. ${ }^{18}$

I shall argue later that Raz's description of the interplay between authoritative legal reasons for action and non-authoritative reasons for action, given the best possible understanding of both the pre-emption and the normal justification thesis, does not imply a complete insulation of secondary from primary reasons and that, for that reason, there is

\footnotetext{
${ }^{15} \mathrm{~J}$. Rat, Authority, law and morality, cit., 214. It is interesting to notice how a similar understanding of the necessary condition for a rational agent to follow authority was used by Gadamer to ground the rationality of following a living tradition. In his Truth and Method (London: Sheed \& Ward, $2^{\text {ns }}$ edition, 1989), Gadamer defines the rationale behind the prejudice according to which following the tradition was in principle correct in terms very similar to Raz's: "But this [blind obedience] is not the essence of authority. Adinittedly, it is primarily persons that have authority; but the authority of persons is ultimately based not on the subjection and abdication of reason but on an act of acknowledgement and knowledge - the knowledge, namely, that the other is superior to oneself in judgement and insight and that for this reason his judgement takes precedence - i.e. it has priority over one's own.", 279.

${ }^{16} \mathrm{~J}$. Raz, The Morality of Freedom, cit., 55.

$17 \mathrm{~J}$. Raz, Authority, law and morality, cit, 214.

18 J. Raz, The Morality of Freedom, cit, 40 41 .
} 
some truth in the theory accotding to which authotitative reasons ate to be weighed against non-authoritative reasons (although, as we shall also see, logically speaking Raz's theory has the best of this exchange). But before dealing with Raz's insulation claim, I shall defend the normal justification thesis against a number of misguided objections and, in doing so, I hope to present it in its strongest version. I also hope that this strong version of the normal justification thesis will make it clear why, in the way Raz conceives it, legitimate authority creates reasons for deciding rather than reasons for action.

First, Raz's normal justification thesis could be said to be innocuous for, in any practical delihetation, one has to know what the correct action in the particular situation is in order to decide if the condition for obedience to authoritative directives stated there (i.e. "that one is likely better to comply with reasons that apply to him" if he accepts the directives of the alleged authotity as binding) is fulfilled. If this were the case, the citizen subject to authority would have to go all the way through the deliberation process and find out what it is righr to do and, if he knows that he would have no reason to follow the authoritative directive, since once he knows what is correct, following the authoritative directive instead of his own reasons cannot make it more probable that the subject would comply with the reasons that apply to him. But this argument would only defeat Raz's conception of legitimate authority under the condition that the only way correctly to judge the probahility of doing the right thing in following the putative authority's directives is to know for sure what the tight answer would be. That is plainly not the case: when one who is completely ignorant on financial markets asks a specialist for advice about investment, one knows that following the advice would lead more probably to the right investment. Under conditions of unlimited time and resources, it might be correct, if one believes self-determination to be valuable, to learn as much as possible about financial markets in order to decide how to invest. Under conditions of limited time and resources, that would he a vety foolish way to decide how to invest one's money.

One could then atgue that this sort of argument of expertise only works under two conditions, one of which cannot be fulfilled in any instance of practical decision-making, while the other cannot be fulfilled in the specific case of moral decision-making. The first is a continuation of the objection above: it is not possible to know if someone is better prepared to take decisions if one cannot compare the decisions that shonld be taken and the advice given. This is again plainly not true, since $I$ can easily recognise that someone is more competent in some areas of decision-making than I am, for instance, from my knowledge of his background or from the fact that in the past he often pointed out mistakes in my practical reasoning which I later came to recognise as mistakes" The other objection is that this sort of justification can only justify technical-practical decisions hecause the ends are set by the person subject to the authority, and the advice is only about how bettet to achieve

19 C. McMahon Autonomy and authority, Philosophy and public Affairs 16 (1987), 309. 
those ends. Without the subject having a notion of what is a correct action beforehand there is no way in which she can judge whether or nor she is more likely to perform the correct action if she follows the advice. So, if I am asking for advise in my investments, I can only regard expert advice as authoritative if I know what a good investment is (let's say, one that gives more return in a shorter time). That is indeed true: one has to have an idea of what counts as morally good which is independent of what the authority says in order to judge if one is more likely to perform the morally correct action when following the authoritative directives. But this is hardly a decisive objection to Raz's theory of legitimate authority, for knowing what is correct in general doesn't imply knowing what is correct in a particular instance. I may believe that promoting equality is the correct thing to do when one is deciding what to do with one's money and still not know if I should give my extra money to the government or to share it amongst all the beggars I know, for I mighr not know what is the best way to achieve equality. Now suppose that someone whom I regard as having more tecbnical knowledge about whether giving the money to the beggars or giving the money to the government will improve equality tells me that giving the money to the beggars is the best course of action, given my aim of furthering equaliry. In this situation, would it be correct for me to give it to the government? Plainly not. This intervention has the potential power of changing my motal landscape. Even if the person I regard as being a specialist is wrong in this particular case and giving money to the government would eventually prove to be more effective in bringing equality about than sharing it out to the beggars, the intervention of this much more knowledgeable person who understands much better than I do the inner mechanisms of the government and the behavior of beggars to whom money is given makes it morally defensible to follow his advice. Acting against his advice may bring about more equality (if the expert turns out to be wrong), but my decision of not following his advice cannot be justified, since it is wrong to perform an action that one has reasons to think is morally worse than an alrernative.

Soper adopted another line of criticism in arguing that Raz's understanding of the authority of law as being grounded in the condition expressed in the normal justification thesis "virtually eliminares the rraditional distinction between theoretical and practical authority" ${ }^{20}$. Soper then goes on to claim that the practical authority of law implies what he calls double pre-emption and, based on that, he establishes the difference between theoretical authority about practical matters and practical authority: practical authority claims complete conrent-independence (which entails pre-emption) whereas theoretical

${ }^{20}$ P. Soper, Legal theory and the claim of authority, cit., 224. 
authority claims only pre-emption. ${ }^{21}$

I have no reason to dispute Soper's claim that there is a distinction between theoretical and practical authority. However, his objection to Raz relies on an assumption that there can be no logical relation of implication between the two sorts of reasons that are the currency of, respectively, theoretical authority and practical authority: reasons to believe and reasons to act. I would like to object to precisely that assumption. Suppose theoretical authority is what Soper claims it is and suppose also that the law (or rather, the law-giver) is taken to have this sort of authority hased on expertise in a particular case in which it issues the directive that action $\mathrm{x}$ is tight. This would be enough teason for a subject that regards the law-giver as theoretically authoritative to have a reason to believe that action $\mathrm{x}$ is right. In turn, beheving that action $\mathrm{x}$ is the right action to perform is a reason to deciding to do $\mathrm{x}$. The apparently sharp separation hetween reasons to believe and reasons to act collapses when one has a reason to believe that an action should be performed ${ }^{22}$. Such a reason is itself a reason to act and this is a fact of the grammar of beliefs. To say 'All applicable reasons support the belief that $\mathrm{x}$ is the right to do, but I don't bave any reason to do x' makes as much sense as saying that 'All applicable reasons support the belief that the cat is on the mar, but there is no reason to believe that the cat is on the mat'. If I am right that a reason to believe that an action is right is a reason to perform that action, it follows that this sort of 'theoretical' authority which gives you those sorts of reasons to believe become ipso facto relevant for the decision-maker's practical reasoning. In short: although a conceptual distinction could be made between theoretical and practical authority, under some conditions, having one implies having the other. If the normal justification thesis succeeds in justifying theoretical authority in a given case, that is, if the putative authority is effectively more likely to get it right, I bave good reasons to decide to follow irs directives, even if they turn out to be wrong.

I hope that from the preceding discussion a picture has emerged of the conditions under which the normal justification thesis can justify the use of authoritative directives as guides for decision-making, even in situations in which the reasons for action point in another direction. In that picture, reasons for deciding in a particular way might be introduced by the normal justification thesis, even if the normal justification thesis does not generate reasons for action.

But Raz's claim is not only that the fulfillment of the condition stated in the normal justification thesis makes the authoritative directive a reason for deciding in a particular way. According to him, the fulfilment of the conditions specified in the normal justification thesis makes the authoritative directive into a reason of a specific kind which relates (or should relate) peculiarly to other kinds of reasons. 'This kind of reason Raz calls 'exclusionary' or 'pre-emptive'. Pre-emptive reasons, as any other 'winning' reason render other reasons for action not applicable to the instant case, but they do so in a particular way. They do not

\footnotetext{
21 idern, 225.

${ }^{22}$ A similar view was put forvard by Postema in his distinctions between direct and indirect guidance of actions by reasons, see G. Postema Jurisprudence as practical philosophy, Legal Theory 4 (1998), 346.
} 
exclude reasons for action by outweighing them, but by the application of "a general principle of practical reasoning which determines that exclusionary reasons always prevail when in conflict with first-order reasons" ${ }^{\text {"23 }}$. Pte-emptive reasons are examples of second-order reasons, which means that they are teasons to act or reftain from acting for a ptimary reason ${ }^{24}$. They can exclude first-order (or primary) reasons by kind. First-order reasons, in Raz's terminology, ate reasons either to perform or not to perform a particular action. Second-order teasons can be rendered inapplicable to one case by another second-otder reason, but can never be challenged by a first-order reason. Challenging a pre-emptive reason with a first-order reason implies either completely denying its pre-emptive nature or denying that its scope covers a particular set of primary reasons. This challenge, says Raz, can only be performed by secondorder reasons. All reasons which concern the pre-emptive nature of a particular reason and the scope of this pre-emption are second-order reasons (to refer to the latter, Raz uses the expression 'scope-affecting reasons"25). It is clear that, for a reason to be pre-emptive of other reasons in a particular instance of practical reason, it is necessary that some issues concerning its pre-emptiveness and the scope of its pre-emption have to be settled.

Practical reasoning, understood here as reasoning which aims at informing action, can be performed at the second-ordet level. Theoretical reasoning which uses primary reasons is not pre-empted by pre-emptive teasons, since "it is merely the action for some of those reasons which is excluded"26. One could still bold an opinion on whether or not the performance of the particular action required by the authority is right. Whar one cannot do, according to Raz, is to act on those reasons. Deliberating, concluding that the authority is wrong and even criticizing the authority are actions that are not excluded by pre-emptive reasons. But the relevant question for a practically rational agent is whether or not Raz's justification for the existence of authontative reasons succeeds in justifying that primary reasons be insulated from secondary reasons in actual contexts of decision-making. Two objections against Raz's thesis look promising, the first questions the credentials of the normal justification thesis, while the second assumes the notmal justification thesis is true, but objects that it cannot justify the insulation between firstorder and second-order reasons. Let us examine them separately.

The first objection tuns as follows: if the normal justification thesis is a moral reason nothing grants in principle that there could be no other moral reason applicable to the situation that could defeat the very normal justification thesis. In order to prove that, Raz would need, so the objection goes, a further argument to justify the systematic priority of the normal justification thesis to all other moral reasons ${ }^{27}$. In the absence of such an argurnent, the suhject should test the normal justification thesis against all available moral teasons and, since the normal justification thesis is a third order reason that explain which sorts of second

\footnotetext{
${ }^{23} \mathrm{~J}$. Raz, Practical Reasons and Norms, cit., 40.

24 idem, 39

is ide(n), 46

25. J. Raz, "The Morality or Freedon, cit., 42.

27 What I consider to be a decisive objection against the existence of systematic prionity (or, as Rawls names it, indexical order) between moral reasons see Ch. Taylor, Leading a life in fncomensurablity, fncomparability and Practical Reason ed. R. Chang Cambridge, MA: Harvard Universicy Press, 1997, 170 183.
} 
order reasons are admissible, no insulation between first-order and second-order reason would be granted. All first order reasons would be, in principle, capable to defeat the reason why they should be insulated, namely, the normal justification thesis. I believe that objection to be wrong, since there is a good reason to believe that moral values cannot defeat the normal justification thesis. Moral values cannot defeat it simply because the normal justification states the correctness of doing what is most likely to be the correct thing to do. If we spell out some of the non-stated conditions for its plausibility (fallibility of human judgement, the existence of different levels of moral insight), the normal justification thesis is not so much a moral directive as it is a self-evident statement about a particular structural feature of morality. That one always aims at doing what one considers to be the right thing is trivial ${ }^{28}$.

But the fact that the normal justification thesis cannot be defeated by substantive moral values does not imply that it can justify pre-emption of reasons. As it often happens with arguments that follow from tautologies, the source of its irrefutability is also the source of its impotence. Let me start to show that by introducing an example. Suppose that the legal authority issues the following directive: "Smoking anywhere in the new building of the Scottish Parliament is forbidden". Let's assume that $I$ have a reason to believe that my abiding by the authoritative ditective makes me more likely to comply with reasons that apply to me than if I try to follow the reasons which apply to me directly. At this point, someone raises the question of whether the authoritative directive is right or wrong and I start wondering whether the thing required by the authority is the best thing to do after all (remember that I am not forbidden to think about those things, only to think of them as reasons for my action). If the reasons I produce against the action being performed are not. good, nothing changes; but suppose I arrive at the conclusion that the action required by the authority is conclusively wrong (rememher that I can hold such an opinion). Can I hold this opinion and at the same time hold the opinion that I am more likely to comply with reasons that apply to me by following the directive than if $I$ try to follow the reasons which apply to me directly? The fact that I know for sure that the authoritative directive is wrong implies that I cannot consistently claim that the normal justification thesis justifies my following the authoritative rule.

What I am trying to get at here is that there is no reason why a jolly good first-otder reason against the authoritative rule wouldn't imply the existence of the following secondorder reason: "it is not probable that I will do what is tight by following the authoritative order". That sort of reasons must be taken into consideration not because the agent

\footnotetext{
22. I refer here to the classical theme of the untenable position of an agent that aims at being acratic.
} 
believes is to be true, but because the notmal justification thesis so demands, since an opinion about the probability of an action being correct cannot be held together with an opinion decisively against its correctness. Probability is the currency of the normal justification thesis and judgements of probability are sensitive to judgements of certainty. Second-order reasons are not precluded from the second level of reasoning and, therefore, they would have to be taken into consideration. It follows that, if primary reasons are to have no influence in the practical deliberation on matters covered by authoritative rules, a reason would have to be provided to explain why those sorrs of second-order reason would be also precluded from decision-making.

Raz does not explicitly provide arguments to explain this furrher preclusion, but he hints at some possible ways in which it could be justified. The first of those hints is to be found in his objection to the thesis that authorirative reasons are prima facie reasons for action which should he weighed against all other reasons for action. Notwithstanding its specific aim, the argument (if it works) hits the much bigger target of justifying complete insulation of secondary reasons from primary reasons.

The argument is a justification for surrendering one's judgement to the authority altogerher. This surrender will be justified if this will decrease my rate of mistakes in a particular area. The first step Raz invites us to take is to

[c]onsider the case in a general way. Suppose I can identify a range of cases in which I am wrong more than the putative aurhority. Suppose I decide because of this to tilt the balance in those cases in favour of this solution. That is, in every case I will first make up my own mind independently of the 'authority's' verdict, and then, in those cases in which my judgement differs from its, I will add a certain weight to the solution favoured by it, on the ground that it, the authority, knows better than $I$. This procedure will reverse my independent judgement in a certain proportion of the cases. Sometimes even after giving the argument favoured by the authority an extra weight it will not win. On other occasions the additional weight will make all the difference. How will $I$ fare under this procedure? If, as we are assuming, there is no other relevant information then we can expect thar in the cases in which I endorse the authority's judgement my rare of mistakes declines and equals that of the authority. In the cases in which even now I contradict the authority's judgement the rate of my mistakes remains unchanged i. e. greater than that of the authority. ${ }^{29}$

At first sight, Raz's conclusion doesn't seem to follow from the premises of his argument. It would seem that the most effective way to enhance ny moral performance is to disobey the authority in all those cases in which the authority is wrong and accept its authority in all those cases in which the authority is right. Following that strategy, my overall performance will be better than it would be had I strictly followed either my own independent judgement

${ }^{29}$ J. Raz, The Morality of Freedom, cit., 68. 
or the authority's directives. But how could this further scenario happen? There is a need for a criterion to decide when it is right to follow the authoritative directive and when it is wrong to do so. Whichever criterion one puts forward, it will question the assumption that the authotity knows better in the field and, if this assumption is defeated, the directives are not regarded as authoritative, for the grounds for authority established by the normal justification thesis would be challenged. One is just specifying an area in which authority is not recognised. As Raz puts it:

Of course sometimes I do have additional information showing that the authority is better than me in some areas and not in others. This may be sufficient to show that it lacks authority over me in those orher areas. The argument about the pre-emptiveness of authoritative decrees does not apply to such cases. ${ }^{30}$

My claim is that this additional information may simply be the fact that the agent is sure thar one particular course of action required by the authority is wrong according to the primary reasons relevant to the particular case. Of course sometimes the agent would believe the authority is wrong, but, not being very sure about it and recognizing the authority's higher comperence in the area, she may be inclined to surrender her judgement. But this doesn't need always to be the case. There is no reason to reject the thesis according to which, in every particular case of practical reasoning in which putative aurhoritative claims authority, the claim of authority is itself open to challenge from primaty reasons.

I believe Raz would not be happy to allow this sort of leakage from first-order into second-order reasoning, since part of the poinr of having rules is to provide "an intermediate level of reasons "31 between deeper level considerations and concrete decisions. Indeed, if this leaking really happens, the pre-emption of primaty reasons may be describing the logical order of a correcr course of reasoning, bur, for the particular agent, legal and non-legal reasons will interact in much the same way as other reasons interact, to wit: strong non-legal reasons for action will be able to debunk specific legal reasons for action.

Raz hints at a second defense of the insulation of secondary reasons from primary reasons. He defends the insulation of authoritative teasons from straightforward substantive reasons against the charge that in every case authoritative directives can be overridden or disregarded if they deviare too much from the reasons which they are meant to reflect ${ }^{32}$. If this is the case, it would be required from 'every person in every case to consider the merits of the case before he can decide to accept an authoritarive instruction' ${ }^{33}$. As he sees it, this ohjection is mistaken because it confuses clear mistakes with big ones, for, in order to

\footnotetext{
30 idem, 68-9.

${ }^{31}$ idem, 58.
} 
estabiish if someone is cleatly mistaken, there is no need for reasoning, and he concludes that.

It is not the case that legitimate powet of authorities is generally limited by the condition that it is defeated by significant mistakes which are not clear. ${ }^{34}$

Raz's concession that clear mistakes by the authority can allow first-order reasons to leak to the second-order level of reasoning is quickly followed by the warning that this does not imply that big mistakes have the same effect. Therefore, there is no need for reasoning thoroughly in order to find out if a mistake was great enough to put authority in check or not. But wouldn't the possibility that the authority makes big mistakes imply that we have the motal obligation of not stopping out investigation at the level of the prima facie moral in tuition? Sontetimes an action which does not seem remarkable prima facie turns out to be clearly wrong after reflection. If, in following authoritative rules, there is a possibility of making a big mistake, one of the obligations one might have is to try to clarify the situation. If, after reflection on the rights and wrongs of the casc, no clear conclusion results, one might decide to follow the authoritative ditective based on the fact, say, that the issuers of the rule seem to have a better idea of what is going on morally than the agent. But that would only happen after first-order practical reflection was carried out ${ }^{3 *}$.

Finally, Raz offers an argument to the effect that 'the pre-emption thesis depends on a distinction between jurisdictional and othet mistakes ${ }^{336}$. Some mistakes by the authority, says $\mathrm{Raz}$, ate ahout factors that determine the limits of the authority's jurisdicrion, others do not concern it. The former are never pre-empted, while the latter always are. Raz offers no teason why this distinction should be taken as morally relevant. In the absence of such justification, my argument against pre-emption stated above cannot be easily put aside. But, even if such justification could he provided, it would have to be grounded on a motal reason systematically prior to the first-order moral reasons. That would be the only way to explain how this moral reason wouldn't itself have to be weighed against first-order moral reasons. Here again the providing an answer to the problem of whether or not there could be systematic priotity (or indexical order, as Rawls would put it) between moral reasons would help to make my point. I can't discuss the idea of moral systematic priority in here, but I don't helieve that it is tenable ${ }^{\hat{7}}$. If no systematic moral priority is justifiable, it follows that no justification that Raz could offer for the motal relevance of the distinction between jurisdictional and other mistakes would he ahle to exclude first-order reasons from an agent's ptactical decision-making process.

\footnotetext{
32 idem, 61 .

33 ibidem.

34 idem, 62 .

35 This paragraph's argument relies on the plausible assumption, stated in chapter one and incorporated one way or another in the arguments of the second, and third chapters, that reasoning makes it more likely that the agent would reach the morally correct conclusion.

3 J. Raz, The Morality of Freedon, cit., 62.

${ }^{37} \mathrm{I}$ take on that problem in the first chapter of my $\mathrm{Ph} \mathrm{D}$ thesis Being appar from Reasons, (Finburgh, 2009).
} 
I believe I have provided by now sufficient evidence for my claim that Raz's attempt to justify the pre-emption of certain reasons fails on its own terms. But perhaps the problem is not so much the idea of pre-emption but Raz's particular conception of pre-emption. Perhaps what is needed is another formulation of Raz's original insight that some reasons should be pre-empted from the deliberation process. Philip Soper tried to provide an alternative account of authoritative reasons' pre-emptive nature in which the idea of preemption is raken one step further. But does Soper's double pre-emption thesis succeed in justifying the insulation of first-order from second-order reasons?

According to Soper, to say that the law is doubly pre-emptive means that it:

typically intends to pre-empt (in the sense of rendering practically irrelevant) deliberations about both the content of the law and the legitimacy of the legal system. ${ }^{38}$

According to the double pre-emption thesis ${ }^{39}$, an agent would not be treating a directive as authoritative if she performs her action because she has good reasons for treating the authoritative directive as legitimate. In this case, even the second level of practical deliberation is closed to the agent and conclusions about the authority being illegitimate would make no difference to her following the authoritative directive. Notice that my objection to Raz's conception of pre-emption does not apply to Soper's. My argument against Raz is simply that good first-order reasons imply a second-order reason that might be able to defeat the reasons one might have in favour of the pre-emption of that particular reason. If it is true that legal reasons do indeed pre-empt all second-order reasons concerning the legitimacy of legislative authority from the decision-making ptocess, my attempt to hring first-order reasons back into the reasoning process fails. The probability calculation on which both Raz's argument for pre-emption and my objection to it relied is not an issue here. However, the double pre-emption thesis is problematic for a number of other reasons, some of which are explicitly (even if not fully) discussed by Soper himself.

Just after introducing the concept of double pre-emption as a feature of law's authority, Soper anticipates the objection that, were his conception of authority right, there would be "an insurmountahle justification problem: if that is what people mean when they claim to

\footnotetext{
${ }^{38}$ P. Soper, Legal theory and the clain of authority, cit., 216.

39 Soper's double pre-enption thesis is similar to Bankowski's thesis that under some conditions an agent should not 'think about it', as stated in, for instance, his Don't think about it: legalism and legality in: Law, Justice and the State ed. Karlsson et al Berlin: Dunker \& Humblot, 1993, 53ff. Given the complexity and the wealth of arguments offered by Bankowski, engaging with them in here would take much longer than 1 can afford.
} 
have authority, the claim could nevet be justified"40. The objection is not spelled out in its entitety by Soper. What lies at its bottom is the fact that, were authority to be understood in the way Soper proposes, there would be no toom for deliberation by the agent subject to authority. Following an authoritative directive would mean not reflecting on the rights and wtongs of the situation, which means, denying one's own practical tationality.

Soper's answer to this objection comprises, first, ptesenting the credentials of his claim by identifying it with a particular tradition of political theory (to which the likes of Hobbes belong) and, second, a theoretical move that pushes justification one step back, so that reason and autonomy are not entitely overridden by authority. In Sopet's own terms;

All that is tequired is that one shift the point of justification hack one level: the problem now would be to offer sufficient reasons (as Hobbes tries to) fot accepting an assertion that the subject is to deliberate neither about the merits of action nor about the metits of the claim of legitimacy. Reason in the end would still jusrify (because suhjects could still deliberate, as Hobbes does, about the claim of double pre-emption); but it would be justification of a far more potent claim - a claim that action must be taken even though the action is wrong on its merits and even though the directing authotity is wtong in its assumption about its own legitimacy. ${ }^{4 t}$

Soper's answer is related to his belief that legal and political philosophers often fail to distinguish between two rather different problems, to wit: the problem of the moral worth of political institutions and the problem of someone's entitlement to he oheyed. Those are indeed diffetent problems, hut Soper believes something else, namely, that the answer to the problem of entitlement to obedience is independent from the answer to the ptoblem of the moral worth of political institutions. This thesis is not argued for in the article we've heen discussing (apart from the reference to the tradition to which his thesis helongs). It is not imunediately clear why his thesis should be right and, indeed, some troublesome consequences follow from it.

The first problem that springs to mind is that reflection on the moral worth of political institutions (i.e. their 'legitimacy'), when entirely divorced from the question whether one should obey the illegitimate authority, seems to have very hittle practical importance. Which sort of action would be required of an agent who concludes that a given political arrangement is not legitimate? Perhaps, one might say, there follows an obligation to try to change the unjust political arrangements. But, if changing them is against the law, I shall not try to change them, for the considerations ahout legitimacy would be pre-empted from my particulat decision-making process. And, indeed, given the fact that dictators and totalitarian governments have much more often safeguarded themselves through those sorts of legal directives than democracies have, it would follow that, in those situations in which the

40 P. Soper, Legal theory and the claim of authority, cit, 216-217.

4) idem, 217. 
concept of legitimation is more badly needed, it would be toothless. Of course, one might say that a theory of entitlement to obedience wouldn't allow for totalitarian regimes to be entitled, but, if that were the case, it would follow that the moral qualities of the authorities would be likely to have some relevance in deciding whether one should obey someone's directives and that is not permitted by the double pre-emption thesis.

Soper's claim that a justification could be provided for always obeying the law regardless of the correctness of the action required and of the legitimacy of the authority could be defended against this charge if it takes a slightly different form. It could be said that the justification is independent of the quality of the action and of the legitimacy of the authority, although, in some particular instances of its application, this reason could be defeated by reasons for not acting in the way requited by law. That thesis was indeed defended by Soper himself in an earlier article $e^{42}$. Regardless of his success in providing such justification, ir should be clear enough that this sort of justification does not pre-empt first-order reasons, since those reasons applied in a concrete case could, in his own terms, defeat the obligation to obey the law.

And that brings me to a second and more conclusive objection. If a justification for acting only on legal reasons is provided, it is either the case that this justification is grounded in a value which is absolute, or it is the case that the value on which the justification for obedience is grounded could be challenged by another value. If the latter is the case, in any situation in which the most important value would be at stake, it should have prevalence and any first-order consideration embodying such a value would have to prevail. If the former is tbe case, it is still possihle that, in an instant case, the value that grounds absolute obedience is better served by disobeying the legal rule, in which case a reason for action conveying this value would have to defeat the justification.

Soper's reformulation of the pre-emption thesis does not incorporate the element that makes Raz's normal justification thesis so difficult to object to: Raz's ground for preemption, the normal justification thesis, is self-evident. No moral value could possibly conflicr with the thesis according to which one has to decide to do what would probably be the right action all things considered, unless one wants to deny the ethical enterprise altogether. Unless Soper offers a justification which is not moral but analytical within ethics, his justification for obeying the law without considering any other reason as practically relevant would always be vulnerable to arguments from moral value (either from superior moral value or for a better application of the same value that grounds obedience to law).

\footnotetext{
${ }^{42}$ P. Soper, The obligation to obey the law, in Issues in Contemporary Legal Philosophy ed. R. Gavison, Oxford: Clarendon Press, 1989, 127-155. In this article, Soper offers reasons for a prima facie obligation to obey the law which could be defeated by other obligations of superior weight (esp. 151-2). Nothing was said about an absolute obligation to obey the law.
} 
Soper's double pre-emption thesis is in some respects similar to Bankowski's thesis that under some conditions an agent should not 'think about it'. However, there is a difference between the two insights and I believe that that difference makes it possible that Bankowski's advice that one should not 'think about it' be correct even if the double preemption thesis is wrong. Befote I move on to present what I consider to be the best way to conceive of fotmal reasons, let me briefly explain the implications of the arguments presented so far in this chapter to Bankowski's thesis that there ate times in which decision makets should think about it and times in which they should not think about it. The point of having rules, Bankowski believes, is partly to provide causes for behaviout, rather than reasons. Rules are partly analogous to physical obstacles we might find when taking a walk. Those obstacles not so much provide us with a reason to walk atound them as they effectively cause us to do it ${ }^{43}$. Rules work at their best when they transcend prescription and become mere descriptions of states of affairs, as Bankowski showed in his analysis of automated systems. We have rules 'so that things get more predictable ${ }^{\text {s4 }}$. But there is something even more strikingly valuable in letting rules cause us to react in certain ways. Rule-following is also constitutive of morality: although it is not tbe whole of morality, Bankowski argues that it is a condition for its possibility. Differently from machines, however, we have an ability to respond to situations that is not simply an ability to react ${ }^{45}$. This abihty to respond is what explains that we might recognise situations in which letting the rules rule our behaviour is not appropriate. As Bankowski puts it:

humans have this facility ... of not only reacting but of correcting - and on this analogy we might think of that as jumping beyond, learning virtue and thus being able to be virtuous in other circumstances. ${ }^{46}$

But in otder to learn this responsive skill, one must engage in the machine-like activity of rule-following ${ }^{47}$. That is the sense in which rule-following (i.e. being causally affected by rules) is constitutive of morality. Now, is any of this inconsistent with my view on pre-emptive reasons? 'That will depend on the scope of Bankowski's claim.

If what Bankowski means is that there are situations in which one should not think at all, and situations in which thinking is required, in which case the 'it' in the phrase 'think

\footnotetext{
${ }^{43} \mathrm{Z}$. Bankowski Living Lawfully, outprint, 128. The outprint in my possession is the camera-ready copy of Bankowski's new book to be published by Kluwex Acadenic Publishers. For that reason, the page references also apply to his forthcoming book.

${ }^{44} \mathrm{Z}$. Bankowski, Living Lawfully, cit., 127.

45 idem, 131-2.

th idem, 132.

4 ibidem.
} 
about it' would mean the same as 'what is the right thing to do', me and Bankowski do not disagree. Indeed I believe that there is an argument to ground the thesis that teasoning is not always the morally best decision-making process, and that means that, in some situations, one should not 'think about it'. Elsewhete ${ }^{48}$, I tried to offer grounds to the claim that a morally good person might be required to let certain facts cause her to perform certain actions, and that would, as far as I can see, help to prove Bankowski's point. I haven't dealt with the problem of whethet or not rules can be conceived as causes, but I see no reason to disagree with Bankowski's conclusions on this respect. Indeed, I believe that conceiving rules as causes is one of Bankowski's most important insights, an insight that actually goes against the majotity views on the nature of rules, that tend to concejve them as reasons to decide to perform an action.

Bankowski believes that the way of life of the law-abiding man requires that he sometimes does not think matters substantively and one of the advantages of doing that is that the law-abiding man's obedience ends up producing the ability of creatively breaking the law (which is part of what being law-abiding is about). However, even on this interpretation of what Bankowski means by 'thinking about it' there may still be some room for disagreement, for I believe that public agents should only act on reasons (were the empirical conditions for reasoning, such as enough time and tesources, to obtain), while Bankowski, on the other hand, makes no qualifications and seems at times to think that the recommendation of not thinking about it crossed the boundaries between puhlic and ptivate agency. If this is so, we do indeed disagree at least pattially.

There is, however, a second interpretation of the phrase 'don't think ahout it'. In this second interpretation, the 'it' in the phrase refers to a formal rule that is applicable to the case at hand and the advice not to think about it means that one should not think about the reasons behind the formal teason. In that interpretation, it is not reasoning that is not recommended, but substantive reasoning. This seems indeed to be the interpretation fayoured by Bankowski when he wites that "We treat the [formall teason as conclusive because it is there, we do not need to inquire behind it and 'think about it ${ }^{349}$. I wish to express no view on whether or not this sott of exclusion can he morally justified for private

48 The grounds for this belief is presented in the first chapter of my Ph D thesis (see note 37).

49. $Z$. Bankowski, Don't think about it: legalism and legality, cit., 53 . 
decision-making, but elsewhere $\mathrm{I}$ argued that public agents must always think about $\mathrm{it}^{50}$. What my argument against Raz and Soper tried to prove is simply that they offer no good reason for public agents not to reason substantively all the time. But if those arguments fail, how can we conceive of formal reasons? That is the question I consider in the next section.

\section{Formal Reasons}

Raz is not the only legal theorist to identify the formality of a legal reason for action with its capacity to exclude other reasons. More importantly, his argument grounded on the normal justification thesis is not the only argument put forward to justify that conception of law's formality. Indeed, thete are arguments which seem to render the exclusionary conception of the formality of law plausible, without making use of the idea of secondary reasons. I shall now move on to investigate whether or not, and in which sense, those arguments are able to justify the exclusion of reasons from decision-making processes. In what follows, I shall use Atiyah's Form and Substance in Legal Reasoning as a paradigmatic presentation of this sort of argument. However, before I deal with the arguments themselves, let me first ask what exactly is the claim that those arguments are supposed to ground.

The claim, as Atiyah puts it, is that, whenever formal reasons are in play, "tthere is no question of weighing one set of factors against another ${ }^{\text {s1 }}$ for ' $[t]$ he formal reason ... simply excludes from consideration any countervailing reason ${ }^{52}$. If the formal reason is good, 'all other argument is irtelevant ${ }^{533}$. Again, what seems to be at stake is an exclusion hy kind of some sorts of reasons by the formal reason. But the claim is often qualified. This exclusion only happens, "within cettain limits ${ }^{154}$. As Atiyah puts it:

If a statute seems ambiguous, or unclear, or if it produces results which seem grossly anomalous or utterly absurd or perhaps even seriously unjust, then courts may avoid applying the statute..$^{55}$

Indeed, one of the differences hetween using formal reasons and being a formalist, according to Atiyah, is openness to the possibility of introducing exceptions to the application of rules. Those qualifications show a certain uneasiness with the conception of legal formality that equates it with the exclusion of certain sorts of teasons from judicial decision-making, an uneasiness that is paradigmatically shown in a passage of Frederick Schauet's Playing by the Rules in which he proposes that exclusionary reasons could be conceived as telling an agent to look just quickly, if possible, at the excluded first-order reason to see if this is one of the cases in which the exclusion of that factor should be disregarded, ... ${ }^{56}$

\footnotetext{
50 Again that problem was subject to scrutiny in my $\mathrm{Ph} D$ thesis, mentioned above, note 37.

${ }^{51}$ P. S. Atiyah, Forn and substance in contract law, cit., 20.

52 idem, 21.

5.3 ibidem.

54 idem, 22.

5 ibidem. Similariy for precedents at 23 .

Fo. Schauer, Playing by the Rules, cit., 91.
} 
Now, as Emilios Christodoulidis has already pointed out, it is not at all clear how the thesis that formal reasons always exclude other reasons for action could be made compatible with the qualification that sometimes some sorts of reasons (e.g. gross injustice) can defeat the formal reason ${ }^{57}$. This leads to an ambiguity in the conception of formal reasons that is clearly expressed in Atiyah's (apparent) paradox that an exclusionary reason 'operates rather like a presumption which is sometimes irrebuttable, but sometimes rebuttable "58. The question that must be asked is which sorts of reasons can be put forward in order for the judge (or anyone subject to the law, for that matter) to consider the formal reason in a particular case to be irrebuttable.

Atiyah presents some reasons thar he believes would justify the exclusionary conception of legal teasons. One of those reasons concerns the low cost-effectiveness of comprehensive reasoning ${ }^{59}$. This argument by no means exhausts the list of arguments that aim at justifying the exclusion of some reasons from the process of decision-making and, to be sure, Atiyah himself offers other such arguments ${ }^{(0)}$. However, the argument of costeffectiveness is a paradigm of the sort of argument for exclusion that does not rely on second-order reasons and that makes it suitable to be used as a means to show wby arguments of its kind cannot justify rbe exclusion of reasons from decision-making processes.

According to the argument of cost-effectiveness, a full investigation on all the relevant reasons for action in any particular case would be way too costly. That cost makes it prohibitive that the public agent effectively uses all reasons that might be in principle applicable to the case. The problem of cost becomes even more serious given the obligation that public agents have of being impartial regarding those who are subject to their authority, for if a judge is to grant a costly investigation to one subject, be would have to do the same to all other subjects in tbe same situation. However, we must bere differentiate between, on the one hand, reasons which are applicahle to the case hut which are defeated by other reasons also applicable to the case and, on the other hand, the reasons that are simply not applicable to the case. Before I consider whether or not the argument of cost-effectiveness has any bearing on situations in which applicable reasons are weighed against one another, let me deal with the problem of the applicability of a reason. A reason might be proved not to apply to the case when the facts do not allow it. The fact that murder was committed is a good reason to sentence the accused to life in prison only if the accused was the one who committed the murder and whether or not this is the case is a matter of investigating facts. Factual investigation might be indeed very costly and the atgument of cost-effectiveness seems to justify that certain factual investigations not be petformed comprehensively.

\footnotetext{
57 $\mathrm{E}$. Christodoulidis The irrationality of merciful legal judgement: exclusionary reasoning and the question of the particular, Law and Philosophy, 18 (1999), at 231.

${ }^{58}$ p. S. Atiyah, Form and substance in contract law,cit., 37.

${ }^{59}$ idem, 24ff.

${ }^{60}$ For an overview of the arguments for the formality of law, see N. MacCormick, The ethics of legalism, Ratio Iuxis, 2, 184-193.
} 
But can the argument for cost-effectiveness justify that formal reasons exclude other reasons that are available to the agent? The argument would only work in those situations if a further argument is provided that proves that weighing already available substantive reasons against each other is significantly mote costly than weighing formal reasons against each other.

More interestingly for my purposes here, there is no systematic priority between the need to be cost-effective and moral reasons. Cost-effectiveness in judicial decisions might be granted some moral value if it is backed by good moral reasons for society to have a legal system at all, such as the value of co-ordination of behaviour or more generally the value of security in human affairs. But those reasons are reasons to be weighed against other moral reasons. This is the sense in which the argument of cost-effectiveness is paradigmatic of the sorts of arguments offered by Atiyah and others for the formal nature of legal rules. Differently from Raz's normal justification thesis, those arguments are ultimately grounded in first-order moral reasons and, for that reason, they cannot claim systematic priority; and hecause they cannot claim systematic priority, they cannot justify the systematic exclusion of other moral values, which might themselves defeat them. The 'formality' of law is a result of a number of good reasons not to reason comprehensively, but those reasons are themselves first-order moral reasons and their nature makes it conceivable that they be sometimes defeated by other moral reasons.

That reading of the formality of law explains why formal reasons operate 'within constraints', that is to say, it explains why there are cases whose solution according to formal reasons is so 'grossly anomalous or utterly absurd or perhaps even seriously unjust' that substantive reasons break through the formality of law in order to influence the decision. In other words, it helps to explain the sense in the apparent paradox that formal teasons are 'sometimes irrebuttable, but sometimes rebuttable'.

Now, is there a reason why one should stick to the exclusionary conception of formal reasons instead of adopting a conception of formal reasons as reasons that are grounded on very important first-order reasons such as, promoting social stability, preventing public agents to decide arbitrarily, or improving co-ordination betwcen the members of society? Christodoulidis presented some reasons why law's formaliry can only be conceived in an exclusionary fashion. He claims that law is an evolutionary achievement that diminishes social complexity and that accepting that first-order reasons leak into the second-order level of justification would 'undo law as an institutional achievement ${ }^{31}$. But why would this undoing be problematic? The problem seems to be the fact that without an exclusionary conception of formality, social complexity would once again increase. There is no denying

6. E. Christodoulidis, The irrationality of merciful legal judgement,cit, 235. 
that social complexity will indeed increase. However, there is no reason to believe that a certain level of social disintegration would not be a price worth paying for more goodness in public decision-making. To be sure, if the social disintegration caused by changing our concept of legal formality would be so great as to make social interaction impossible (under conditions of double contingency) that would be a very good teason indeed to stick to our evolutionary achievement of conceiving formality in an exclusionary way. But I see no reason why the very important first-order reasons mentioned above as good grounds for deciding according to the law wouldn't be able to guarantee a very high level of social integration. This would leave the space open to other first-order teasons to enter juchicial decision-making, as well as the decision-making of law-abiding citizens in general, for the strong first-order reasons they have to stick to the law are, as is any first-order reason, defeasible.

In this conception of formality, formal and substantive reasons are entangled, the formaliry of formal reasons being guaranteed by strong substantive reasons. That conception of formality is, therefore, highly sensitive to suhstantive arguments, and that is, perhaps, the next evolutionaty achievement of social systems. Indeed, various instances of changes in legal practice hear witness to the increased importance of substantive argument in judicial decision-making. The most striking example is perhaps the growth of the concept of good faith in German case law, notably in the first quarter of the $20^{\text {th }}$ century ${ }^{62}$. The judicial use of the concept has defied all attempts to circumscrihe 'good faith' to a strict definition or to reduce it to a numerus clausus list of rules. Good faith seems to be simply a door through which weighty suhstantive considerations came to be used as grounds for the decision of German courts. Contemporary substantive considerations are as much included in "good faith' as substantive considerations inspired in roman and romanistic law $w^{63}$. It has recently been defined as a requirement of fairness in private affairs and, in this conception, good faith is clearly a window within the legal system for considerations of substance in judicial decisionmaking.

Having pointed out the differences between Christodoulidis's approach to formality and mine, let me just briefly show where they coincide. Both Christodoulidis and I shate a preoccupation with the colonization of the ethical by the legal, of the suhstantive hy the formal. His way out of this colonization is his understanding of the concept of mercy as a

\footnotetext{
${ }^{12}$ On the evolution of the concept of good faith, see J. Martins Costa A Boa-fé no Direito Privado:sistema e tópica no processo obrigacional (São Paulo: Ed. Revista dos Tribunais, 1999).

${ }^{4}$. As, e.g., the clause forbidding the venire contra factuin proprium. For other sorts of substantive considerations that made theit way into German legal decisions through the concept of grood faith, see F. Wieacker El Principio General de la Buena fe (Madrid: Civitas, 1976; J L de los Mozos, trans).
} 
doorway into a more complex world where reflexivity (roughly what I call plenary reasoning) has its space. Mine is to redefine formality so that reflexivity becomes inherent to formal (and amongst them legal) reasons, in a way that actually resembles the old positivist call not to act on legal norms without having good moral reasons backing your action.

\section{Conclusion}

I expect to have proven in this paper that the sort of strategy proposed by Raz (and partially adopted by Soper) in order to insulate authoritative from substantive reasons does not succeed. That means that neither Raz's justification for pre emption nor Soper's offer a good reason for public agents not to reason substantively all the time.

It would seem that destroying such strategies renders formal reasons useless in practical decision-making that aims at being morally correct. I believe that is correct. Yet, what would follow from that? Only that a new conception of formal reasons needs to be built in which formal reasons are not in opposition to substantive reasons, but are somehow derived from actual substantive reasons. 